\title{
Pathophysiologic Mechanisms of Computer Vision Syndrome and its Prevention: Review
}

\author{
Abiy Maru Alemayehu' ${ }^{1 *}$ and Mogess Maru Alemayehu ${ }^{2}$ \\ ${ }^{1}$ Department of Optometry, University of Gondar, Ethiopia \\ ${ }^{2}$ Department of paraclinical studies, University of Gondar, Ethiopia
}

*Corresponding author: Abiy Maru Alemayehu, Department of Optometry, University of Gondar, Gondar, Ethiopia.

Received Date: October 21, 2019

Published Date: November 12, 2019

\section{Abstract}

Nowadays, a computer is used at home, institution and everywhere which results in different ocular and non- ocular symptoms. These include asthenopia, blurred vision, double vision, neck pain, back pain and headache to mention some, which is known as computer vision syndrome. In this report, different kinds of literature were reviewed which shows the pathophysiologic process underlining computer vision syndrome and its management options.

From the pathophysiologic point of view, vision related, ocular surface related, and digital screen related conditions are responsible for the development of computer vision syndrome. Since the causes of computer vision syndrome are multiple, a combination of different treatment modality is needed. It includes refractive error correction, dry eye treatment, good ergonomic practice and others. Explaining the pathophysiologic mechanism of computer vision syndrome and the treatment options will help clinicians to manage computer vision syndrome accordingly.

Keywords: Computer vision syndrome; Dry eye; Blink rate; Digital eyestrain; video display terminals; Gondar

\section{Introduction}

Nowadays the computer has changed and eased the lives of many people in the workplace. Office work, conducting research, preparation of notes and other computer related works have always involved a range of activities, such as typing, filing, reading, and writing. With the evolution of the computer, all these tasks can now be completed using one device. Desktop, tablets, smart phones and personal computers are some of the visual display units, used for different purposes in institutions, at workplaces and other recreational areas. But apart from their advantage, usage of visual display units have risk of developing computer vision syndrome (CVS) which is one of the emerging public eye health problems in the world. CVS is one of the most important occupational hazard of the $21^{\text {st }}$ century which affects 70 percent of all computer users [1].

The American Optometric Association defines CVS or digital eye strain as a "group of eye and vision-related problems that result from prolonged computer, tablet, e-reader and cell phone use" [2]. Nearly more than half of the world's populations are using the internet as described by Internet world stats [3]. It is estimated that nearly 60 million people suffer from CVS globally, and that a million new cases occur each year [4].

The most encountered symptoms during computer usage are reduced blink rate, tired eye, headache, neck pain, blurring of vision eye strain [5-8]. It is also stated that the performance of the human vision system is reduced due to long period usage of computer and discomfort lightening conditions [9]. It is also known that blue light emitted from a computer screen can reduce the amount of melatonin [10]. Annoying reflections [11], head position and direction of gaze during performing on visual display units can lead to symptoms of CVS [5].

CVS significantly impairs workplace productivity and reduces the quality of life by placing unusual strain on human physical well-being as well as reduce job satisfaction and lost work time $[1,12,13]$. It is also known that CVS can reduce work accuracy in specific tasks by as much as $40 \%$ [1]. Reading from a computer screen can reduce understanding ability compared to reading test on print paper [14], which in turn may affect schooling or work- 
related performance. Due to the errors made during computer use, the economic impact is paramount [15]. Working with visual display units is also recognized as a cause of short and long term physical and mental stress $[16,17]$.

Therefore, detailing the pathophysiology, the clinical features, the predisposing factors, the diagnosis and the preventive mechanisms of CVS is very important so as to alleviate symptoms, to increase productivity and to minimize risks among visual display users. Dealing CVS in broad also gives clinicians on how to approach their patient in the real situation.

\section{Pathophysiology of CVS}

The focusing mechanism of human eyes are not similar for printed text and for visual display units but, give a response in different ways. Reading materials on printed text and computer has much difference in terms of viewing distance, gaze angles, blinking rate, the appearance of texts and demand of accommodation as well as in widening of a palpebral fissure during reading. Each printed letters are made up of a well-defined character throughout its surface, whereas VDT letters are made up of pixels which are the result of the electronic beam striking the phosphor-coated rear surface of the screen $[18,19]$. Each pixel is bright at its center and with decreasing brightness towards the periphery. So that the human eyes cannot sustain focus on the pixel characters [20]. Instead the focusing system lags behind the computer screen due to the vertical position of gaze which is preferred position by computer user relative to reading a printed text [21]. This point is called the dark focus. Hence the eyes are constantly relaxing to resting point of accommodation or dark focus and struggling to gain focus on the pixels character frequently. This frequent focusing and refocusing of the eye by the ciliary body creates fatigue to the eye and causes accommodative symptoms related to CV [22]. This lag of accommodation so leads ocular symptoms related to CVS. In addition to these the images formed by pixels and raster lack sharp edges in turn which creates an under stimulation of accommodation and causes lag of accommodation behind the screen due to blurred characters of texts [20,22]. See Figure 1 below. Therefore, visual work in a computer is demanding and includes frequent saccadic eye movements (ocular motility), accommodation (continuous focusing) and vergence (alignment demands), all of which involve continuous relaxation and contraction of the eye muscles [23] (Figure 1).

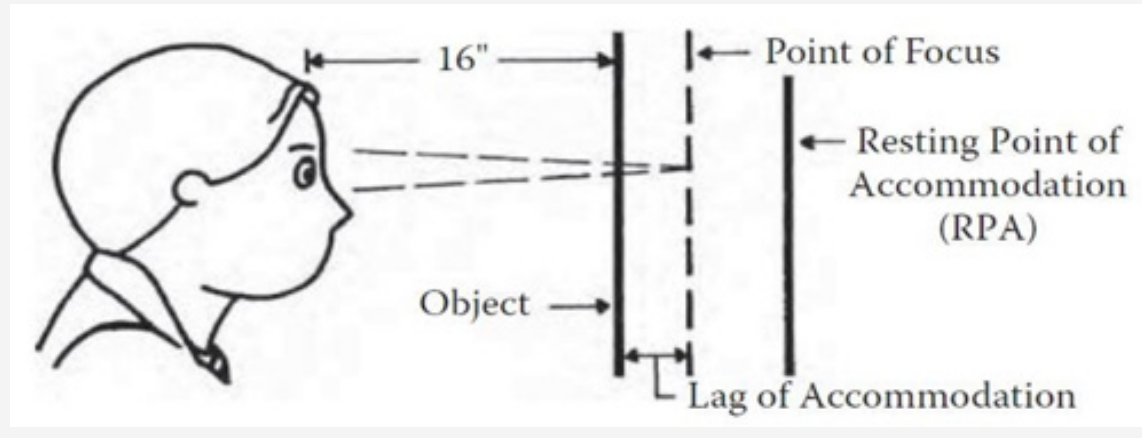

Figure 1: Focusing mechanism during viewing on a computer [22].

\section{Clinical Feature of CVS or Symptomatology of CVS}

Finding the exact causes of computer vision syndrome is not a simple issue, but it is a combination of several factors like prolonged working hours, inadequate breaks and constantly staring at a screen are some of the important causes of computer vision syndrome. Symptoms of CVS are categorized into four main groups:

- $\quad$ asthenopia,

- ocular surface-related,

- $\quad$ visual, and

- $\quad$ extraocular [24].

It is believed that screen factors, such as brightness, contrast, screen glare, and screen refresh rate, increase stress on the visual apparatus, thereby increase computer use related problems [25]. Asthenopic symptoms are related to the eye strain due to many factors which are associated with prolonged computer use $[13,24,26,27]$. Eye strain may result from prolonged computer usage as it causes a decreased amount of accommodation, development of heterophoria at a near task and near point of convergence removal.
The results of this suggested that the weakness of these important visual functions could be the cause of eyestrain in computer operators [8]. Higher position of the computer screen relative to eye level is also another cause of eye strain [28]. Ocular surface related symptoms include dry eyes [29]. As noted from different studies, working with computers leads to reduced blinking rate and increased corneal exposure due to primary gaze position of the monitor [24]. This results in dry eye symptoms. In addition to these, environmental conditions like poor air condition, glare and others during computer operation can lead to dry eyes [30]. The other ocular surface related symptom is irritated eyes or ocular discomfort [31]. When we see why it happens, prolonged usage of visual display leads to tear film instability in turn this results in corneal epithelium injury which stimulates nerve endings. As a result, it causes ocular discomfort [32]. A study suggests that the usage of computers for as little as 45 minutes can reduce blink rates by $57 \%$, which leads ocular surface disorders like keratoconjunctivitis [33]. In order to fixate for a long period of time and to achieve clear visual information blink may be inhibited from high cognitive demand or low-legibility conditions [34]. 
Visual symptoms of CVS comprise blurring of vision, double vision, difficulty in focus, and headache [5]. Visual performance may be affected by different factors like display medium, target to background appearance and light wavelength [19]. Blurred vision symptoms can result from refractive errors [5,22,28,35], improper prescription lenses, presbyopia, or environmental factors like the poor position of gaze, excessive amount of glare, poor quality of screen resolution [22]. The other probable causes of blurred vision are accommodative infacility, lead or lag during visual display unit use. Tear abnormality, muscle fatigue or vergence problem are also another important cause of blurred vision [36].

Extraocular symptoms such as neck pain, shoulder pain, psychosocial stress and backache are often due to poor ergonomic design and posture $[4,20]$. These extraocular symptoms may be developed from improper viewing position during computer use as well $[17,37]$. The diagnosis of headache is not simple, but it occurs towards the middle or the end of the day after extensive use of computers [22]. Symptomatology of clinical features are displayed in the following consecutive figures (Figure 2-4). And the symptoms are summarized below as well (Table 1) (Figures 2-4).

Table 1: Four major symptoms in computer vision syndrome $[1,7,17,22,24,31,39]$.

\begin{tabular}{|c|c|c|}
\hline Symptom Category & Symptoms & Possible Causes \\
\hline Asthenopic & $\begin{array}{c}\text { Eyestrain, Sore eyes, } \\
\text { Tired eyes }\end{array}$ & $\begin{array}{c}\text { Binocular vision } \\
\text { Accommodation }\end{array}$ \\
\hline Ocular surface related & $\begin{array}{c}\text { Dry eyes, Watery eyes, } \\
\text { Irritated eyes, Contact } \\
\text { lens problems }\end{array}$ & \\
\hline Visual related & $\begin{array}{c}\text { Blurred vision, The } \\
\text { slowness of focus } \\
\text { change, Double vision, } \\
\text { Presbyopia }\end{array}$ & $\begin{array}{c}\text { Refractive error } \\
\text { Accommodation } \\
\text { Binocular vision } \\
\text { Presbyopic correction }\end{array}$ \\
\hline Extra-ocular related & $\begin{array}{c}\text { Neck pain, Back pain, } \\
\text { Shoulder pain }\end{array}$ & $\begin{array}{c}\text { Computer screen } \\
\text { location Sitting } \\
\text { position }\end{array}$ \\
\hline
\end{tabular}

\section{Vision related}

\section{Refractive}

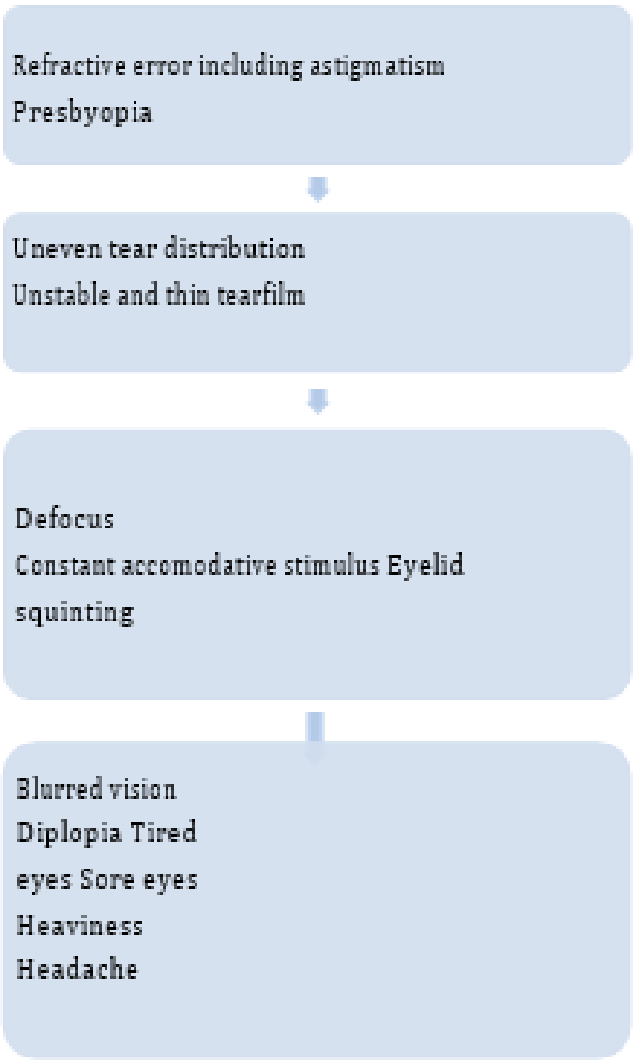

\section{Oculomotor}

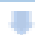

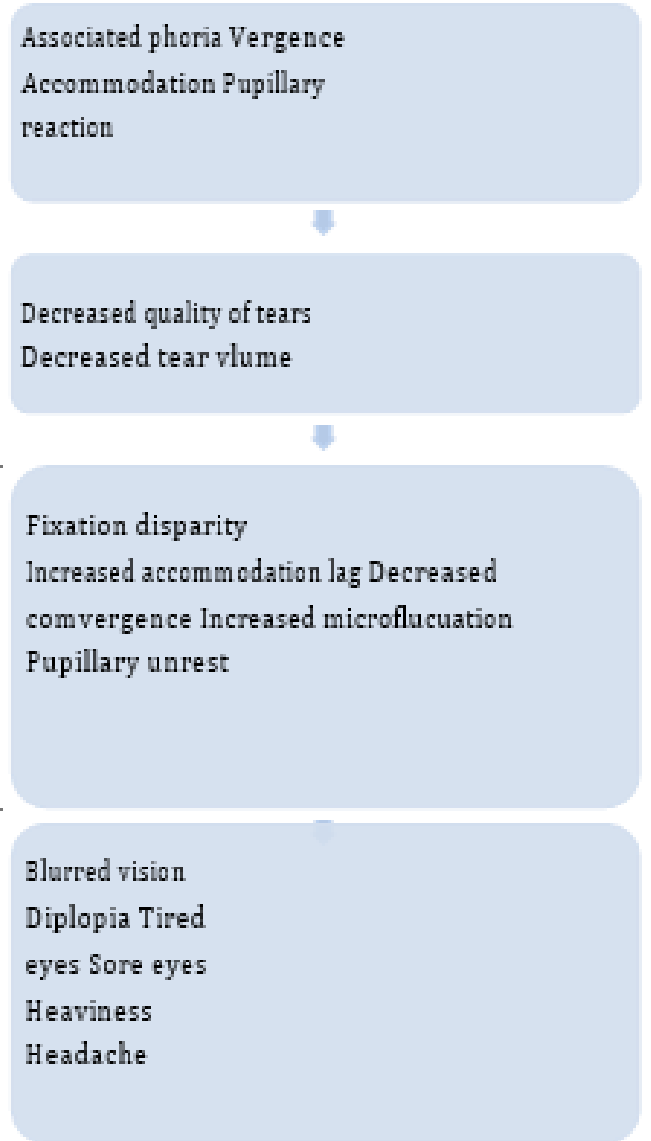

Figure 2: Vision-related digital eye strain symptomatology [38]. 


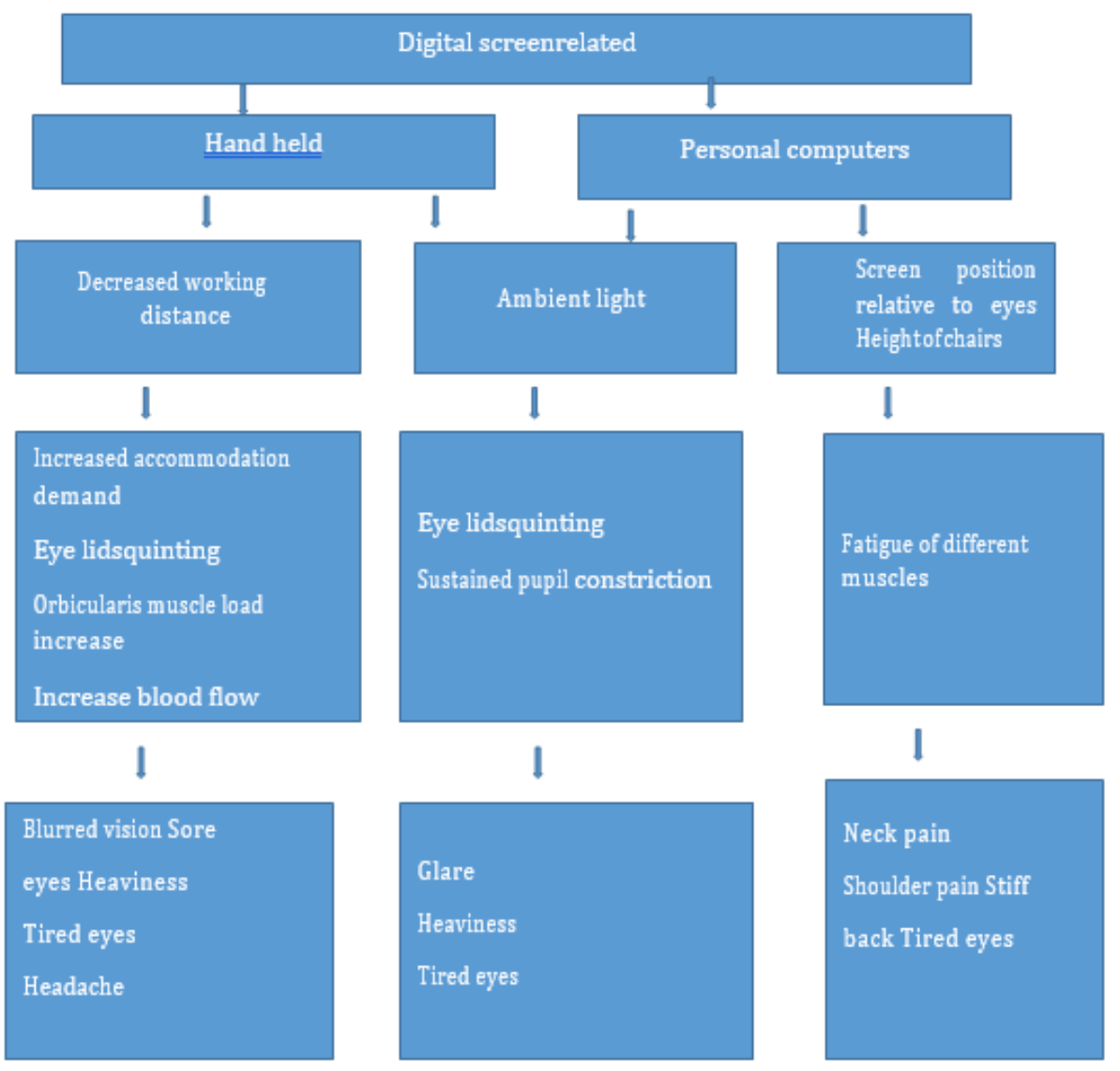

Figure 3: Digital screen-related digital eye strain symptomatology [38].

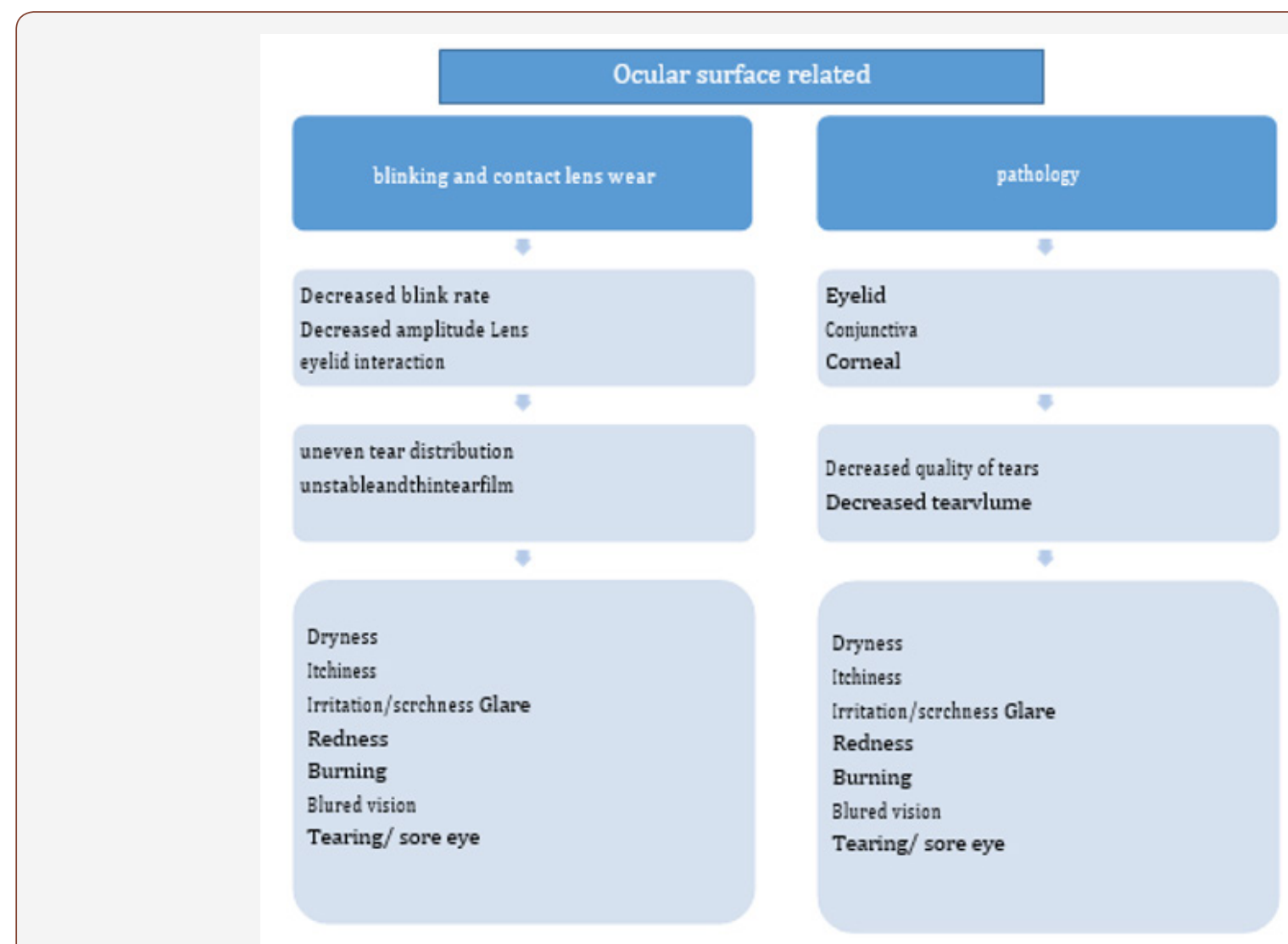

Figure 4: Ocular surface-related digital eye strain symptomatology [38] 


\section{Risk Factors for the Development of CVS}

A study showed that there is a relation between the symptoms and signs and the time used per day and duration per year of exposure to the computer $[4,13,40,41]$. Not taking a break between activity is also one of the factors that predispose individuals to develop CVS [42]. The other important factor that leads to the development of CVS is the presence of glare as indicated in different studies [43]. The lower resolution of the computer display is supposed to cause visual fatigue (need reference). In general personal, environmental and device related factors lead to the development of CVS $[12,17,44]$. Summary of risk factors are displayed below (Table 2).

Table 2: Risk factors contributing to computer vision syndrome.

\begin{tabular}{|c|c|}
\hline Personal factor & $\begin{array}{c}\text { Reduced eye movement Poor seating posture } \\
\text { Improper viewing distances Improper viewing } \\
\text { angle Not taking break Ocular diseases Medical } \\
\text { diseases Ageing }\end{array}$ \\
\hline Environmental factor & $\begin{array}{c}\text { Poor lighting Imbalanced of light between the } \\
\text { computer screen and the surrounding } \\
\text { Computer factor }\end{array}$ \\
\hline $\begin{array}{c}\text { Reduced refresh rate, Poor resolution, Poor } \\
\text { contrast, The glare of the display }\end{array}$ \\
\hline Visual related & $\begin{array}{c}\text { Blurred vision, The slowness of focus change, } \\
\text { Double vision, Presbyopia }\end{array}$ \\
\hline Extra-ocular related & Neck pain, Back pain, Shoulder pain \\
\hline
\end{tabular}

\section{Diagnosis of CVS}

Computer vision syndrome is a diagnosis of exclusion. In addition to the detailed routine ocular examinations, the history taking component must include number and type of devices being used, viewing distance and gaze angle for each device, amount of time used per device and other important parameters like size, contrast and brightness used during the task [37]. After taking a history, the physical examination must include refraction [22,45], binocular vision assessment $[34,44,46]$ and tear film evaluation [6], but not limited to these. Evaluating blink rate is also considered as an important tool for diagnosis as well as treatment purpose for CVS $[29,47,48]$.

\section{Prevention and Treatment of CVS}

There is no single management option for the treatment of computer vision syndrome as the cause is multifactorial. The multidirectional approach is recommended to alleviate symptoms of computer vision syndrome.

Correction of refractive error is the most important means of treating CVS, because it can reduce the stimulus to accommodation [31]. Specially designed computer glasses are known to reduce computer vision if prescribed at an optimal distance [26,35,49]. The other one is the management of binocular dysfunction as it is possible to improve accommodation demand by looking down and in simultaneously $[21,26]$ Treating dry eye is also the other known method to prevent CVS $[17,50,51]$. Triphala eye drops are known to reduce as well as to increase visual function as indicated by Gangamma M, et al. [27]. Supplement of omega 3 fatty acid improves tear stability as well as decreases symptoms which caused due to usage of the visual display unit [52]. Visual discomfort and visual fatigue can be lessened by wearing short wavelength-blocking eyeglasses during computer tasks [2,17,23, 26,33,53,54].

Modification of the working environment is also one of an important and easy method to minimize the risk of developing CVS. Ergonomic factors are known to cause CVS [13,42,55-57]. So, adjusting sitting position, distance from the computer display, horizontal and vertical gaze angle, as well as the height of the computer display relative to the level of the eye is recommended to prevent the development of computer vision syndrome. This working includes the lightening of the room, brightness of the computer display, contrast and height of the letters. For example, increasing the height of the letters gives more comfort as indicated in the study of Lee, et al. [18]. Reducing screen luminance is one of the methods to increase the blinking rate [58]. Proper room lightening during computer use is also one of the methods to prevent CVS $[26,51]$. The mean distance of viewing a computer is suggested to be in the range of $60-80 \mathrm{~cm}[2,28]$. Another important ergonomics practice is the usage of ' $1,2,10$ ' rule that shows proper distance for cell phones and e-books to be at one feet (30 $\mathrm{cm})$, for computers to be at 2 feet $(60 \mathrm{~cm})$ and for televisions to be at ten feet $(3 \mathrm{~m})$ [59]. The other important solution is to design forearm support and vertical mouse design [44]. Using 20-20-20 rule is a most and simple method to prevent CVS, which means after 20 minutes of computer usage, look at distance of 20 feet for 20 seconds [2,35]. Delivering training about good ergonomics practice is an important method to decrease workstation related musculoskeletal problems among computer users [60,61]. Table 3 shows summary of recommended computer distance and angle from different standards (Table 3).

Table 3: Recommendations for Computer Monitor Locations, from Some National and International Standards [22].

\begin{tabular}{|c|c|c|c|}
\hline Standard & Distance & Vertical Angle & $\begin{array}{c}\text { Horizontal } \\
\text { Angle }\end{array}$ \\
\hline $\begin{array}{c}\text { Australian } \\
\text { Standard (AS, } \\
\text { 1990) }\end{array}$ & $\begin{array}{c}\text { 35 to } 75 \mathrm{~cm} \text { for } \\
\text { the primary } \\
\text { display }\end{array}$ & $\begin{array}{c}15 \text { to } 45 \text { degrees } \\
\text { downward from } \\
\text { horizontal, } \\
\text { eyelevel gaze; } \\
\text { refers to this angle } \\
\text { as "optimal" }\end{array}$ & $\begin{array}{c}\text { Within } 15 \\
\text { degrees on } \\
\text { either side of } \\
\text { the centerline } \\
\text { of the viewer, } \\
\text { for the primary } \\
\text { display }\end{array}$ \\
\hline $\begin{array}{c}\text { International } \\
\text { Standards } \\
\text { Organization } \\
\text { (ISO,1992) }\end{array}$ & $\begin{array}{c}\text { At least } 40 \\
\text { cm, and is } \\
\text { dependent upon } \\
\text { the size of the } \\
\text { characters }\end{array}$ & $\begin{array}{c}\text { 0 to } 60 \text { degrees } \\
\text { downward from } \\
\text { horizontal, } \\
\text { eyelevel gaze; } \\
\text { "preferred" is } \\
20 \text { to } 22 \text { degrees } \\
\text { downward }\end{array}$ & \\
\hline $\begin{array}{c}\text { HFES (This } \\
\text { is revision } \\
\text { of ANSI 100- } \\
\text { 1988.) }\end{array}$ & $\begin{array}{c}50 \text { to } 100 \mathrm{~cm} \\
\text { to } 60 \text { degrees } \\
\text { downward from } \\
\text { horizontal, } \\
\text { eyelevel gaze; } \\
\text { center at15 to 20 } \\
\text { degrees downward }\end{array}$ & $\begin{array}{c}\text { Within } 17.5 \\
\text { degrees on } \\
\text { either side of } \\
\text { the centerline } \\
\text { of the viewer }\end{array}$ \\
\hline
\end{tabular}

\section{Conclusion}

Computer vision syndrome is an emerging public eye health problem as it is highly prevalent among computer users. Personal 
factors, computers characteristics and working environment play a great role in the development of computer vision syndrome. So, managing computer vision syndrome, requires a multidirectional approach to avoid or reduce the condition.

\section{Acknowledgement}

None.

\section{Conflict of Interest}

There is no conflict of interest relating to the content of this review.

\section{References}

1. Charpe NA, Kaushik V (2009) Computer vision syndrome (CVS): Recognition and control in software professionals. Journal of Human Ecology 28(1): 67-69.

2. American Optometric Association (2019) Computer vision syndrome.

3. Internet World stats (2019) Internet users in the world.

4. Sen A, Richardson SA (2007) study of computer-related upper limb discomfort and computer vision syndrome. J Hum Ergol (Tokyo) 36(2): 45-50.

5. Antona B, Barrio AR, Gasco A, Pinar A, Gonzalez Perez M, et al. (2018) Symptoms associated with reading from a smartphone in conditions of light and dark. Appl Ergon 68: 12-17.

6. Nakaishi H, Yamada Y (1999) Abnormal tear dynamics and symptoms of eyestrain in operators of visual display terminals. Occup Environ Med 56(1): 6-9.

7. Teo C, Giffard P, Johnston V, Treleaven J (2019) Computer vision symptoms in people with and without neck pain. Appl Ergon 80: 50-6.

8. Trusiewicz D, Niesłuchowska M, Makszewska Chetnik Z (1995) Eyestrain symptoms after work with a computer screen. Klin Oczna 97(1112): 343-345.

9. Wang Q, Xu H, Gong R, Cai J (2015) Investigation of visual fatigue under LED lighting based on reading task. Optik 126(15-16): 1433-1438.

10. Figueiro MG, Wood B, Plitnick B, Rea MS (2011) The impact of light from computer monitors on melatonin levels in college students. Neuro Endocrinol Lett 32(2): 158-163.

11. Council NR (1983) Video displays, work, and vision: National Academies Press, USA.

12. Akinbinu T, Mashalla Y (2014) Impact of computer technology on health: Computer Vision Syndrome (CVS). Medical Practice and Reviews 5(3): 20-30.

13. Ranasinghe $P$, Wathurapatha W, Perera Y, Lamabadusuriya D, Kulatunga $S$, et al (2016) Computer vision syndrome among computer office workers in a developing country: an evaluation of prevalence and risk factors. BMC Res Notes 9(1): 150.

14. Mangen A, Walgermo BR, Brønnick K (2013) Reading linear texts on paper versus computer screen: Effects on reading comprehension. International journal of educational research 58: 61-68.

15. Del Mar Seguí M, Cabrero García J, Crespo A, Verdú J, Ronda E (2015) A reliable and valid questionnaire was developed to measure computer vision syndrome at the workplace. Journal of clinical epidemiology. 68(6): 662-673.

16. Smith MJ (1997) Psychosocial aspects of working with video display terminals (VDTs) and employee physical and mental health. Ergonomics 40(10): 1002-1015.

17. Loh K, Redd S (2008) Understanding and preventing computer vision syndrome. Malays Fam Physician 3(3): 128-130.

18. Lee DS, Ko YH, Shen IH, Chao CY (2011) Effect of light source, ambient illumination, character size and interline spacing on visual performance and visual fatigue with electronic paper displays. Displays 32(1): 1-7.
19. Chang PC, Chou SY, Shieh KK (2013) Reading performance and visual fatigue when using electronic paper displays in long duration reading tasks under various lighting conditions. Displays 34(3): 208-214.

20. Wimalasundera S (2009) Computer vision syndrome. Galle Medical Journal 11(1).

21. Ripple PH (1952) Variation of accommodation in vertical directions of gaze. Am J Ophthalmol 35(11): 1630-1634.

22. Anshel J (2005) Visual ergonomics handbook: CRC Press, USA.

23. Association AO (1997) The effects of computer use on eye health and vision.

24. Blehm C, Vishnu S, Khattak A, Mitra S, Yee RW (2005) Computer vision syndrome: a review. Surv Ophthalmol 50(3): 253-262.

25. Chawla A, Lim TC, Shikhare SN, Munk PL, Peh WC (2019) Computer Vision Syndrome: Darkness Under the Shadow of Light. Can Assoc Radiol J 70(1): 5-9.

26. Sheedy JE, Shaw McMinn PG (2002) Diagnosing and treating computerrelated vision problems: Elsevier Health Sciences.

27. Gangamma M, Poonam MR (2010) A clinical study on "Computer vision syndrome" and its management with Triphala eye drops and Saptamrita Lauha. Ayu 31(2): 236-239.

28. Jaschinski W, Heuer H, Kylian H (1998) Preferred position of visual displays relative to the eyes: a field study of visual strain and individual differences. Ergonomics 41(7): 1034-1049.

29. Portello JK, Rosenfield M, Chu CA (2013) Blink rate, incomplete blinks and computer vision syndrome. Optom Vis Sci 90(5): 482-487.

30. Piccoli B (2003) A critical appraisal of current knowledge and future directions of ergophthalmology: consensus document of the ICOH Committee on'Work and Vision'. Ergonomics 46(4): 348-406.

31. Rosenfield M (2011) Computer vision syndrome: a review of ocular causes and potential treatments. Ophthalmic Physiol Opt 31(5): 502515.

32. Weisenthal R (2015) 2016 basic and Clinical Science Course (BCSC): sect. 8: external disease and cornea. San Francisco: American Academy of Ophthalmology.

33. Abelson MB, Ousler III GW (1999) How to fight computer vision syndrome. Review of ophthalmology 6(7): 114-116.

34. Sheppard AL, Wolffsohn JS (2018) Digital eye strain: prevalence, measurement and amelioration. BMJ open ophthalmology 3(1): e000146.

35. Tribley J, McClain S, Karbasi A, Kaldenberg J (2011) Tips for computer vision syndrome relief and prevention. Work 39(1): 85-87.

36. Coles-Brennan C, Sulley A, Young G (2019) Management of digital eye strain Clin Exp Optom 102(1): 18-29.

37. Yan Z, Hu L, Chen H, Lu F (2008) Computer Vision Syndrome: A widely spreading but largely unknown epidemic among computer users. Computers in Human Behavior 24(5): 2026-2042.

38. Hall L, Coles Brennan C (2015) More screen time= more digital eye strain. CL Spectrum 30(6): 38-40.

39. Bali J, Neeraj N, Bali RT (2014) Computer vision syndrome: A review. Journal of clinical ophthalmology and research 2(1): 61-68.

40. Mussa A (2016) Computer vision syndrome. Adv Ophthalmol Vis Syst 4(3): 00110.

41. Arumugam S, Kumar K, Subramani R, Kumar S (2014) Prevalence of Computer Vision Syndrome among Information Technology Professionals Working in Chennai. World J Med Sci 11(3): 312-314.

42. Assefa NL, Weldemichael DZ, Alemu HW, Anbesse DH (2017) Prevalence and associated factors of computer vision syndrome among bank workers in Gondar City, northwest Ethiopia, 2015. Clin Optom (Auckl) 9: 67-76.

43. Lin CW, Yeh FM, Wu BW, Yang CH (2019) The effects of reflected glare and visual field lighting on computer vision syndrome. Clinical and Experimental Optometry. 
44. Parihar J, Jain VK, Chaturvedi P, Kaushik J, Jain G, et al. (2016) Computer and visual display terminals (VDT) vision syndrome (CVDTS). Med J Armed Forces India 72(3): 270-276.

45. Rosenfield M (2016) Computer vision syndrome (aka digital eye strain). Optometry in Practice 17(1): 1-10.

46. Phamonvaechavan P (2017) A comparison between effect of viewing text on computer screen and $\mathrm{iPad}^{\circledR}$ on visual symptoms and functions. Siriraj Medical Journal 69(4): 185-189.

47. Divjak M, Bischof H (2009) Eye Blink Based Fatigue Detection for Prevention of Computer Vision Syndrome. MVA.

48. Miyake Kashima M, Dogru M, Nojima T, Murase M, Matsumoto Y, et al. (2005) The effect of antireflection film use on blink rate and asthenopic symptoms during visual display terminal work. Cornea 24(5): 567- 570.

49. Butzon SP, Sheedy JE, Nilsen E (2002) The efficacy of computer glasses in reduction of computer worker symptoms. Optometry 73(4): 221-230.

50. Vaz F, Henriques S, Silva D, Roque J, Lopes AS, et al. (2019) Digital Asthenopia: Portuguese Group of Ergophthalmology Survey. Acta Med Port 32(4): 260-265.

51. Barthakur R (2013) Computer vision syndrome. Internet Journal of Medical Update 8(2): 1-2.

52. Bhargava R, Kumar P, Arora Y (2016) Short-term omega 3 fatty acids treatment for dry eye in young and middle-aged visual display terminal users. Eye Contact Lens 42(4): 231-236.

53. Lin JB, Gerratt BW, Bassi CJ, Apte RS (2017) Short-wavelength lightblocking eyeglasses attenuate symptoms of eye fatigue. Invest Ophthalmol Vis Sci 58(1): 442-447.
54. Downie LE (2017) Blue-light filtering ophthalmic lenses: to prescribe, or not to prescribe? Ophthalmic and Physiological Optics 37(6): 640-643.

55. Agarwal S, Goel D, Sharma A (2013) Evaluation of the factors which contribute to the ocular complaints in computer users. J Clin Diagn Res $7(2): 331-335$.

56. Dessie A, Adane F, Nega A, Wami SD, Chercos DH (2018) Computer Vision Syndrome and Associated Factors among Computer Users in Debre Tabor Town, Northwest Ethiopia. Journal of environmental and public health 2018.

57. Rahman ZA, Sanip S (2011) Computer user: demographic and computer related factors that predispose user to get computer vision syndrome. International Journal of business, humanities and technology 1(2): 8491.

58. Benedetto S, Carbone A, Drai Zerbib V, Pedrotti M, Baccino T (2014) Effects of luminance and illuminance on visual fatigue and arousal during digital reading. Computers in human behavior 41: 112-119.

59. Bilton N (2011) I Live in the Future \& Here's How It Works: Why Your World, Work and Brain Are Being Creatively Disrupted: Crown Business, USA.

60. Rasoulzadeh Y, Gholamnia R (2012) Effectiveness of an ergonomics training program on decreasing work- related musculoskeletal disorders risk among video display terminals users. Health Promot Perspect 2(1): 89-95.

61. Mirmohammadi SJ, Mehrparvar AH, Olia MB (2012) Mirmohammadi $M$. Effects of training intervention on non-ergonomic positions among video display terminals (VDT) users. Work 42(3): 429-433. 